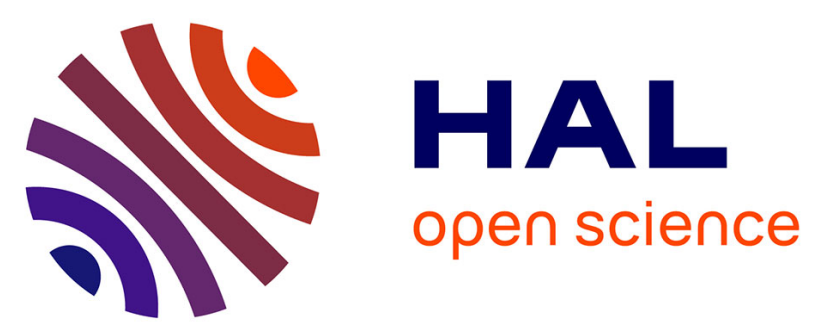

\title{
Clinical and socioeconomic predictors of pregnancy termination for fetuses with congenital heart defects: a population-based evaluation.
}

Karim Tararbit, Thi Thanh Thao Bui, Nathalie Lelong, Anne-Claire Thieulin, François Goffinet, Babak Khoshnood

\section{To cite this version:}

Karim Tararbit, Thi Thanh Thao Bui, Nathalie Lelong, Anne-Claire Thieulin, François Goffinet, et al.. Clinical and socioeconomic predictors of pregnancy termination for fetuses with congenital heart defects: a population-based evaluation.: Pregnancy termination for fetuses with CHD. Prenatal Diagnosis, 2013, 33 (2), pp.179-86. 10.1002/pd.4043 . inserm-00912708

\section{HAL Id: inserm-00912708 https://www.hal.inserm.fr/inserm-00912708}

Submitted on 26 Feb 2014

HAL is a multi-disciplinary open access archive for the deposit and dissemination of scientific research documents, whether they are published or not. The documents may come from teaching and research institutions in France or abroad, or from public or private research centers.
L'archive ouverte pluridisciplinaire HAL, est destinée au dépôt et à la diffusion de documents scientifiques de niveau recherche, publiés ou non, émanant des établissements d'enseignement et de recherche français ou étrangers, des laboratoires publics ou privés. 
2 Clinical and socioeconomic predictors of pregnancy termination for fetuses with congenital heart

3 defects: A population-based evaluation.

\section{Authors}

5 Karim Tararbit*, MD, MS, Thi Thanh Thao Bui*, MD, MS, Nathalie Lelong*, MS, Anne-Claire

6 Thieulin*, MS, François Goffinet*, §, MD, PhD, Babak Khoshnood*, MD, PhD

7 * Inserm, UMR S953, Recherche épidémiologique sur la santé périnatale et la santé des femmes et 8 des enfants, UPMC, Université Paris-6,

9 § Maternité Port Royal, Hôpital Cochin Saint-Vincent-de-Paul, Assistance Publique Hôpitaux de

10 Paris, Université Paris-Descartes, 123, boulevard de Port-Royal, 75679, Paris Cedex 14, France

11 Short title: Pregnancy termination for fetuses with CHD

\section{Word Counts:}

- Abstract: 199

- Text: 2952

\section{Tables: 5}

16 Funding sources. The Paris Registry of Congenital Malformations received financial support

17 from INSERM (Paris, France) and the Institut de Veille Sanitaire (Saint-Maurice, France).

18 Disclosure of interest.None of the authors have any financial or other conflicts of interest with

19 reference to the material in this manuscript. The funding sources had no role in the writing of the 20 manuscript and the decision to submit it for publication. 


\section{Bulleted statement.}

23 Most of the literature on TOPFA for congenital heart defects includes single-center hospital-based

24 studies. Moreover, few studies have evaluated both socioeconomic and clinical factors that could

25 be associated with the risk of TOPFA for congenital heart defects.

26 Using population-based data, we found that, in addition to severity of congenital heart defects,

27 early prenatal diagnosis and maternal characteristics are highly associated with the probability of

28 TOPFA for isolated congenital heart defects.

$31 \quad$ Please address all correspondence to:

32 Karim Tararbit

33 INSERM U953

34 Maternité Port-Royal, 6ème étage

$35 \quad 53$ avenue de l'Observatoire

3675014 Paris

37 France

38 tel : (33 1) 42345570

39 fax : (33 1) 43268979

40 email : karim.tararbit@inserm.fr 


\section{ABSTRACT}

44 Objectives. 1) Evaluate the probability and timing of termination of pregnancy for fetal anomaly 45 (TOPFA) for all congenital heart defects (CHD) and categories of CHD; 2) assess clinical and 46 socioeconomic predictors of TOPFA for isolated CHD excluding ventricular septal defects (VSD).

47 Methods. Using population-based data from the Paris Registry of Congenital malformations, we 48 assessed the probability of TOPFA and gestational age at TOPFA. We used logistic regression to 49 estimate the adjusted effects of maternal characteristics, clinical factors (CHD type, fetal growth 50 restriction, nuchal translucency measurement, and gestational age at prenatal diagnosis) on the 51 odds of TOPFA.

52 Results. The proportion of TOPFA for prenatally diagnosed CHD was $46 \%$ for all CHD 53 combined, $82 \%$ for CHD associated with chromosomal anomalies and $27 \%$ for isolated CHD54 VSD excluded. Isolated CHD-VSD excluded diagnosed before 22 weeks of gestational age had a 55 3.2-fold higher odds of TOPFA (Adjusted-OR 3.2, 95\%CI 1.4-7.1). Maternal occupation was not 56 associated with the odds of TOPFA. Women of African origin had a ten-fold lower odds of TOPFA 57 than women of French origin (Adjusted-OR 0.1, 95\% CI 0.02-0.4).

58 Conclusion. In addition to severity of CHD, early prenatal diagnosis and maternal characteristics

59 were highly associated with the probability of TOPFA for CHD.

60 Keywords. Termination of pregnancy for fetal anomaly, prenatal diagnosis, congenital heart 61 defects, epidemiology, risk factors. 
63 Congenital heart defects (CHD) are the most frequent congenital anomalies. ${ }^{1}$ Progress in fetal 64 ultrasonography has conducted to an increase in the overall proportion of congenital 65 malformations, and in particular CHD, that are prenatally diagnosed. The most severe cases of 66 CHD can be accurately diagnosed during fetal life. ${ }^{2-4}$ Ultrasonography screening for CHD at 13/14 67 weeks of gestation has shown to have good performances and has been proposed to be routinely 68 performed in low-risk population. ${ }^{5}$ In case of positive screening, a more detailed scan must be 69 performed by a pediatric cardiologist in the beginning of the second trimester. ${ }^{6}$ In high risk 70 population, a specialized scan should be offered in first trimester. ${ }^{7}$ The overall effect of prenatal 71 diagnosis on the outcome of fetuses with CHD is difficult to evaluate due to higher severity of 72 cases that are prenatally diagnosed. ${ }^{8}$ Nevertheless, the beneficial effect of prenatal diagnosis on 73 morbidity and mortality has been shown for certain CHD such as transposition of great arteries or 74 coarctation of the aorta. ${ }^{2,9,10}$

75 For the most severe CHD, termination of pregnancy for fetal anomaly (TOPFA) following prenatal 76 diagnosis may be an option to discuss with parents. ${ }^{6,11,12}$ Previous studies have shown that timing 77 and accuracy of prenatal diagnosis, existence of associated anomalies, available treatment options 78 and prognosis are factors associated with decision-making regarding TOPFA in case of CHD. ${ }^{6,12,13}$ 79 However, most studies have examined TOPFA for CHD with single-center hospital-based 80 data ${ }^{11,13,14}$ and few population-based studies exist regarding TOPFA for CHD. ${ }^{2,3,15}$ Moreover, few 81 studies have evaluated both socioeconomic and clinical factors that could be associated with the 82 risk of TOPFA for CHD.

83 Using population-based data from the Paris Registry for Congenital Malformations, we 1) 84 examined the proportion of TOPFA and gestational age at TOPFA for all CHD and categories of 85 CHD and 2) assessed the role of socioeconomic and clinical factors associated with TOPFA and 
86 gestational age at TOPFA for cases of "isolated" CHD excluding ventricular septal defects (i.e., 87 "major" CHD with no other associated anomalies). 
MATERIAL AND METHODS

\section{Data}

90 We used data from the Paris Registry for Congenital Malformations which registers all cases of

91 birth defects and chromosomal anomalies among live-borns, still-borns ( $\geq 22$ weeks of gestation),

92 and TOPFA at any gestational age. The Registry covers the population of women who live in

93 Greater Paris area (Paris and its surrounding suburb) and deliver or have a pregnancy termination

94 in a Parisian maternity unit. The annual number of deliveries in our population is about 38000.

95 The Paris Registry is a member of the European Network of Registries of Congenital 96 Malformations (EUROCAT) ${ }^{16,17}$ and of the International Clearinghouse for Birth Defects

97 Surveillance and Research. ${ }^{18,19}$

98 The Registry follows the EUROCAT methodology and quality of data is routinely monitored by 99 both EUROCAT and the National Committee of Registries in France. The review of procedures 100 regarding confidentiality of data is overseen by both the National Committee of Registries and the

101 National Committee of Informatics and Freedom. Data are based on medical records and are 102 collected from several sources including maternity units, neonatology wards, and cytogenetic and 103 pathology services.

104 Our study population comprised women who lived and delivered or had a pregnancy termination 105 in Paris during the period 2001-2007.

\section{Methods}

107 We conducted an observational study to i) describe the proportion of TOPFA after prenatal 108 diagnosis and gestational age at TOPFA and ii) assess predictors associated with the risk (odds) of 109 TOPFA and gestational age at TOPFA.

110 Proportions of TOPFA and gestational age at TOPFA were estimated for the following categories:

111 i) all CHD combined, ii) all isolated CHD, iii) isolated CHD-ventricular septal defects (VSD) 
112 excluded; the latter category was constituted in order to represent major isolated CHD that often

113 requires intervention, iv) CHD associated with chromosomal anomalies and v) CHD associated

114 with malformations of other systems.

115 Predictors of the odds of TOPFA were assessed for isolated CHD-VSD excluded. Variables 116 considered as predictors were maternal characteristics (age, occupation, geographic origin and 117 gravidity), clinical characteristics (nuchal translucency, intra-uterine growth retardation (IUGR), 118 gestational age at prenatal diagnosis, gestational age at TOPFA, and category of CHD) and year of 119 TOPFA. Maternal age was coded in three categories $(\leq 34,35-37, \geq 38)$ based on the higher risk of 120 chromosomal anomalies in women aged 35 or more and the fact that at the time of our study 121 reimbursed amniocentesis or chorionic villus sampling was available to all women over 38 years 122 of age in our study population. Maternal occupation comprised the following categories: 123 professional, intermediate, administrative/public service, and none. Maternal geographic origin 124 was coded as: French, African and other countries. Gravidity was coded in two categories: 125 primigravida and multigravida. Nuchal translucency measured at first trimester scan was 126 categorized as: normal, abnormal and not done (i.e. women who had not their 1st trimester scan). 127 IUGR was as noted in medical records and coded in two categories (no/yes). Gestational age at 128 prenatal diagnosis was dichotomized in gestational age $\leq 22$ and $>22$ weeks, as 22 weeks is the 129 recommended term for 2 nd trimester scan in France. Gestational age at TOPFA was analyzed as a 130 continuous variable. Isolated cases of $\mathrm{CHD}$ were classified into 4 subcategories by a pediatric 131 cardiologist (T.B.) based on the diagnosis recorded in the Registry database: i) functionally 132 univentricular CHD, ii) so-called conotruncal CHD, iii) complex CHD (at least two cardiac defects 133 combined excluding VSD) and iv) other CHD. 
136 Data were analyzed using standard descriptive statistics (mean, standard deviation (SD), and

137 frequency). Chi-square test, or Fisher's exact test when appropriate, and ANOVA test were used

138 for univariate analyses of the differences between groups. The associations between clinical and

139 socioeconomic factors and the odds of TOPFA were assessed using logistic regression models.

140 Observations with missing values were excluded from the multivariate analyses. The statistical

141 significance level was set at $\alpha=0.05$. All analyses were done with Stata 10 software (Statacorp, 142 TX, USA).

\section{RESULTS}

145 During the study period, 1465 cases of CHD were registered, among which 66\% ( $\mathrm{n}=968)$ were 146 isolated CHD, $16 \%(\mathrm{n}=230)$ were CHD associated with chromosomal anomalies and $18 \%(\mathrm{n}=267)$ 147 with anomalies of other systems (including genetic syndromes). VSD accounted for half of the 148 cases of isolated CHD $(51 \%, \mathrm{n}=495)$.

149 Gestational age at prenatal diagnosis was missing for $0.4 \%$ of fetuses. There were no missing data 150 for the outcome of the pregnancy (live-birth, still-birth, TOPFA). Maternal occupation and nuchal 151 translucency were missing for $8 \%$ of cases. For the other variables, data were missing for less than $1521 \%$ of fetuses.

153 Table 1 summarizes the proportions of prenatal diagnosis and TOPFA for all CHD, and 154 subcategories of CHD. Overall, 48\% (703/1465) of cases were prenatally diagnosed and TOPFA 155 occurred for $22 \%$ of all cases of CHD (325/1465). Prenatal diagnosis was made for $35 \%$ of all 156 isolated CHD (339/968), 58\% of isolated CHD - VSD excluded (274/473) and 79\% of CHD 157 associated with chromosomal anomalies (182/230).

158 Among prenatally diagnosed CHD ( $\mathrm{n}=703)$, TOPFA was performed in $46 \%(325 / 703)$ of cases. 159 The highest proportion of TOPFA was observed for CHD associated with chromosomal anomalies 
160 (82\%, 148/182). CHD associated with chromosomal anomalies accounted for $45 \%$ of cases of 161 TOPFA (148/325). Proportion of TOPFA for isolated CHD - VSD excluded was 27\% (74/274). 162 Among those 74 cases of TOPFA for isolated CHD - VSD excluded, hypoplastic left heart 163 syndrome accounted for half $(51 \%, \mathrm{n}=38)$.

164 Overall, the mean gestational age at prenatal diagnosis was 20.4 weeks (SD 0.26) for the study 165 population (Table 2). Mean gestational age at prenatal diagnosis was lowest for cases associated 166 with chromosomal anomalies (19.1, SD 0.38) and highest for isolated CHD - VSD excluded (21.9, 167 SD 0.39). The mean gestational age at TOPFA was 23.2 weeks (SD 0.29) for the study population 168 (Table 2). The average gestational age at TOPFA was lowest for CHD associated with 169 chromosomal anomalies (21.7, SD 0.45) and highest for isolated CHD - VSD excluded (24.8, SD 170 0.46). The mean duration between prenatal diagnosis and TOPFA was 2.8 weeks and was similar 171 for all subcategories of CHD. More than half (57\%) of TOPFA for CHD associated with 172 chromosomal anomalies were performed before 22 weeks of gestation vs. $17 \%$ for isolated CHD 173 VSD excluded. We did not find a significant time trend in the gestational age at TOPFA over the 174 study period.

175 Table 3 summarizes the univariate analyses of the association of TOPFA for isolated CHD - VSD 176 excluded with maternal characteristics and clinical factors. TOPFA was significantly less frequent 177 for mothers of African origin (11\% vs. 33\% for mother of French origin and $28 \%$ for women of 178 other origin, $\mathrm{p}=0.003$ ). TOPFA was significantly more frequent for CHD diagnosed before 22 179 weeks of gestation ( $42 \%$ vs. $17 \%$ for CHD diagnosed after 22 weeks, $\mathrm{p}<0.001$ ), for functionally 180 univentricular CHD and complex CHD (60\% and $34 \%$ respectively vs. $21 \%$ for conotruncal CHD 181 and $11 \%$ for other CHD, $\mathrm{p}<0.001)$. No statistically significant associations were observed for the 182 other factors, although TOPFA tended to be more frequent in case of IUGR (50\% vs. 26\%, $183 \mathrm{p}=0.09$ ). 
184 Table 4 summarizes the multivariate analyses of the association of TOPFA for isolated CHD -

185 VSD excluded with maternal characteristics and clinical factors. CHD diagnosed before 22 weeks 186 of gestational age had a 3.2- fold higher odds of TOPFA than those diagnosed later (adjusted OR 187 3.2, 95\%CI $1.4-7.1$ ). IUGR (adjusted OR 6.6, 95\%CI 0.9 - 51.0), single ventricle (adjusted OR 188 21.3, 95\%CI 7.7 - 59.0) and complex CHD (adjusted OR 5.8, 95\%CI 1.7 - 17.4) were also 189 associated with higher odds of TOPFA but confidence intervals were fairly wide. Maternal 190 occupation was not associated with the odds of TOPFA. However women of African origin had a 191 10-fold lower odds of TOPFA than women of French origin (adjusted OR 0.1, 95\% CI $0.02-0.4$ ).

192 There was no significant timr trend in the odds of TOPFA during the study period.

193 Table 5 summarizes the results of the univariate analyses of predictors of mean gestational age at 194 TOPFA. Sample sizes were relatively small and no statistically significant associations were 195 observed. In particular maternal characteristics were not significantly associated with gestational 196 age at TOPFA whereas an increased nuchal translucency measurement tended to be associated with 197 a lower gestational age at TOPFA although the association was not statistically significant $198 \quad(\mathrm{p}=0.13)$. 
201 Using population-based data from the Paris Registry for Congenital Malformations, we found that

202 the overall rate of termination of pregnancy for fetal anomaly (TOPFA) for cases with congenital 203 heart defects (CHD) prenatally diagnosed was 46\%. The highest probability of TOPFA was 204 observed for CHD associated with chromosomal anomalies (82\%). A prenatal diagnosis before 22 205 weeks of gestation was associated with a 3.2-higher odds of TOPFA for isolated CHD - VSD 206 excluded. Maternal occupation was not independently associated with the probability of TOPFA. 207 However, mothers of African origin had a 10 fold-lower odds of TOPFA than women of French 208 origin.

209 It is difficult to know the extent to which our results may be generaliseable to other countries.

210 France represents a particular context for prenatal diagnosis and TOPFA as it pursues an active and 211 highly codified policy of prenatal diagnosis. In contrast to many European countries, TOPFA is 212 authorized in France regardless of gestational age for incurable fetal diseases or life-threatening 213 maternal conditions. ${ }^{20}$ Proportions of prenatal diagnosis and TOPFA, in particular for CHD, tend 214 to be higher in France as compared to those observed in other countries ${ }^{1,15,16}$ even though 215 differences in the post-natal diagnosis and the period of registration of cases in the postnatal period 216 across countries complicate the interpretation of observed differences in the proportion of prenatal 217 diagnosis for CHD in different countries.

218 We observed a lower proportion of TOPFA for isolated CHD as compared to CHD associated with 219 chromosomal anomalies or anomalies of other systems, which is consistent with the data from the 220 European surveillance of congenital anomalies (Eurocat) network of registries of congenital 221 anomalies. ${ }^{4,21}$ We also observed that the risk of TOPFA was significantly higher for functionally 222 univentricular CHD, which is due to the fact that the outcomes for functionally univentricular 223 CHD remain poor. ${ }^{22,23}$ 
224 Socioeconomic factors are known to be associated with the likelihood of TOPFA for chromosomal 225 anomalies, in particular Down syndrome. ${ }^{24-27}$ This association has been little studied in the specific 226 case of $\mathrm{CHD}^{27}$ In a hospital-based study, Zyblewski et al. ${ }^{13}$ did not find an association between 227 socioeconomic factors and TOPFA. We found that maternal geographic origin, but not occupation, 228 was strongly associated with the risk of TOPFA for isolated CHD. Access to information about 229 prenatal diagnosis and TOPFA and parental decision making for chromosomal anomalies have 230 been shown to be influenced by preferences and cultural factors ${ }^{26,28}$, although the barriers to 231 effective access to full information may also include language barrier since interpreters are often 232 not available. The same association between TOPFA and cultural factors may exist for isolated 233 CHD. We did not observe an association between maternal age and the probability of TOPFA for 234 isolated CHD, suggesting that the overall higher rates of TOPFA for CHD in older women were 235 due to the higher proportions of associated chromosomal anomalies. Prenatal diagnosis and 236 TOPFA occurred earlier in case of CHD associated with chromosomal anomalies. ${ }^{28,29}$ This may 237 have been in part due to an increased nuchal translucency measured in the first trimester which is 238 more likely to occur for both chromosomal anomalies and certain CHD. It is also possible that 239 even in the absence of an increased nuchal translucency, cytogenetic studies conducted after 240 prenatal diagnosis of a CHD diagnosed earlier in pregnancy were more likely to reveal an 241 associated chromosomal anomaly.

242 The average interval between prenatal diagnosis and TOPFA was similar (two weeks) for both 243 isolated CHD and CHD associated with chromosomal anomalies and was consistent with other 244 studies. $^{4,29}$ This interval corresponds to the time necessary for a multidisciplinary discussion and 245 for parents to make their decision.

246 The proportion of TOPFA in fetuses with CHD has been shown to be higher when prenatal 247 diagnosis occurs earlier. ${ }^{4,5,12}$ We also found that isolated CHD - VSD excluded diagnosed before 
24822 weeks had a 3.2-fold higher odds of TOPFA in comparison to those diagnosed later. TOPFA

249 may indeed be more easily accepted by families at an earlier gestational age. ${ }^{4}$ In addition, CHD

250 diagnosed earlier may have been on average more severe (associated with poorer prognosis) and

251 hence be more likely to be a candidate for TOPFA. Even though we partially took into account 252 severity of CHD in our analyses, a residual effect of severity as one explanation for the association

253 between earlier timing of prenatal diagnosis and probability of TOPFA cannot be excluded.

254 For isolated CHD - VSD excluded, gestational age at TOPFA tended to be lower in case of 255 abnormal nuchal translucency. Indeed, a more detailed examination of fetal heart is usually 256 performed after an abnormal nuchal translucency measurement on first trimester ultrasonography 257 and may therefore conduct to the earlier diagnosis of a CHD. ${ }^{30,31}$

258 Our study has certain limitations. Due to small sample sizes, confidence intervals were fairly wide 259 indicating the limited precision of our estimates. We did not adjust for paternal characteristics due 260 to a high frequency of missing data. Nevertheless, paternal characteristics are strongly correlated 261 with maternal characteristics and are therefore, at least partially, taken into account by maternal 262 adjustment. Data were complete for pregnancy outcome and there were few missing data for the 263 factors included in the analyses. Bias in our estimates due to missing data is therefore unlikely. 264 However, residual bias or residual confusion due to missing data or confounding factors not taken 265 into account in this study cannot be excluded. The strengths of our study are a large sample size 266 and population-based data.

267 We explored specific associations that may exist between the risks of TOPFA and different 268 categories of CHD defined a priori based on anatomic and/or clinical criteria and classified by a 269 pediatric cardiologist. A caveat that needs to be considered is that our criteria for defining these 270 categories can be arguable. Moreover, alternative and more detailed groupings exist ${ }^{32,33}$, which 271 may provide additional information for estimating the probability of TOPFA for CHD. However, 
272 our results suggest that specific associations exist between the categories of CHD as defined in our

273 study and the probability of TOPFA without necessarily implying that the categories investigated

274 in our study are the most appropriate ones to use in this setting.

275 Diagnostic bias may have occurred as not all fetuses with a prenatally diagnosed CHD resulting in

276 TOPFA had a fetal pathology examination. Therefore, in these cases ascertainment of CHD was

277 based only on prenatal findings. Nevertheless, these cases represented a minority of the overall 278 study population.

\section{CONCLUSION}

281 In conclusion, TOPFA occurred for $27 \%$ of isolated CHD - VSD excluded that were prenatally 282 diagnosed, $82 \%$ of CHD associated with chromosomal anomalies and 53\% of CHD associated 283 with anomalies of other systems. Prenatal diagnosis of isolated CHD - VSD excluded before 22 284 weeks of gestation was associated with a 3.2-fold higher odds of TOPFA. Women of African 285 origin had a 10-fold lower odds of TOPFA than women of French origin. The categories of CHD 286 reflecting its severity were also significantly associated with the risk of TOPFA for isolated CHD 287 VSD excluded. Gestational age at TOPFA tended to be earlier in fetuses with an abnormal nuchal 288 translucency. Timing of TOFPA was explained essentially by timing of prenatal diagnosis and the 289 time interval between prenatal diagnosis and TOPFA appeared to be essentially constant for all the 290 clinical and socioeconomic categories included in our study. 
291 Ethics approval.

292 No ethics approval was necessary for this study.

293 Contribution to authorship.

294 B. K. conceived the study. T.T.T.B. conducted the main statistical analyses. K.T., N. L. and A-C. T. 295 assisted with statistical analysis. K.T. wrote the first draft of the manuscript with T.T.T.B. and B.K.

296 F.G. contributed to the conceptualization of ideas and made suggestions about the required 297 analyses. All of the authors contributed to the interpretation of findings and revisions of the article. 
2991 Dolk H, Loane M, Garne E. Congenital heart defects in Europe: prevalence and perinatal 300 mortality, 2000 to 2005. Circulation. 2011;123:841-9.

3012 Khoshnood B, De Vigan C, Vodovar V, et al. Trends in prenatal diagnosis, pregnancy 302 termination, and perinatal mortality of newborns with congenital heart disease in France, 1983303 2000: a population-based evaluation. Pediatrics. 2005;115:95-101.

3043 Garne E, Loane M, Dolk H, et al. Prenatal diagnosis of severe structural congenital 305 malformations in Europe. Ultrasound Obstet Gynecol. 2005; 25:6-11.

3064 Garne E, Stoll C, Clementi M. Evaluation of prenatal diagnosis of congenital heart diseases 307 by ultrasound: experience from 20 European registries. Ultrasound Obstet Gynecol. 2001;17:38630891.

3095 Carvalho JS. Fetal heart scanning in the first trimester.Prenat Diagn. 2004; 24:1060-7.

3106 Simpson JM. Impact of fetal echocardiography. Ann Pediatr Cardiol. 2009;2:41-50.

3117 Carvalho JS, Moscoso G, Tekay A, et al. Clinical impact of first and early second trimester 312 fetal echocardiography on high risk pregnancies. Heart. 2004;90:921-6.

3138 Botto LD, Correa A. Decreasing the burden of congenital anomalies/ an epidemiologic 314 evaluation of risk factors and survival. Progress in Pediatric Cardiology. 2003;18:111-21.

3159 Bonnet D, Coltri A, Butera G, et al. Detection of transposition of the great arteries in fetuses 316 reduces neonatal morbidity and mortality. Circulation. 1999;99:916-8.

31710 Franklin O, Burch M, Manning N, et al. Prenatal diagnosis of coarctation of the aorta 318 improves survival and reduces morbidity. Heart. 2002;87:67-9.

31911 Allan LD, Cook A, Sullivan I, Sharland GK. Hypoplastic left heart syndrome: effects of fetal 320 echocardiography on birth prevalence. Lancet. 1991;337:959-61.

$321 \quad 12$ Allan LD, Huggon IC. Counselling following a diagnosis of congenital heart disease. Prenat 
32313 Zyblewski SC, Hill EG, Shirali G, et al. Chromosomal anomalies influence parental 324 treatment decisions in relation to prenatally diagnosed congenital heart disease. Pediatr Cardiol. $325 \quad 2009 ; 30: 1105-11$.

32614 Tennstedt C, Chaoui R, Korner H, Dietel M. Spectrum of congenital heart defects and 327 extracardiac malformations associated with chromosomal abnormalities: results of a seven year 328 necropsy study. Heart. 1999;82:34-9.

32915 Garne E, Khoshnood B, Loane M, et al. Termination of pregnancy for fetal anomaly after 23 330 weeks of gestation: a European register-based study. Bjog. 2010;117:660-6.

331 Khoshnood B, Greenlees R, Loane M, Dolk H. Paper 2: EUROCAT public health indicators 332 for congenital anomalies in Europe. Birth Defects Res A Clin Mol Teratol. 2011;91 Suppl 1:S1633322.

33417 Greenlees R, Neville A, Addor MC, et al. Paper 6: EUROCAT member registries: 335 organization and activities. Birth Defects Res A Clin Mol Teratol. 2011;91 Suppl 1:S51-S100.

33618 Cocchi G, Gualdi S, Bower C, et al. International trends of Down syndrome 1993-2004: 337 Births in relation to maternal age and terminations of pregnancies. Birth Defects Res A Clin Mol 338 Teratol. 2010;88:474-9.

33919 Registre des Malformations de Paris. Surveillance épidémiologique et diagnostic prénatal 340 des malformations : Evolution sur vingt-sept ans (1981-2007). 2010. [WWW document].URL 341 http://www.unites.inserm.fr/download.asp?download=stockfile/U149/documents/registre/brochure 342 27ans.pdf [accessed on 22 August 2012].

34320 Boyd PA, Devigan C, Khoshnood B, et al. Survey of prenatal screening policies in Europe 344 for structural malformations and chromosome anomalies, and their impact on detection and 345 termination rates for neural tube defects and Down's syndrome. Bjog. 2008;115:689-96. 
34621 Garne E, The EUROCAT working group. Prenatal diagnosis of six major cardiac

347 malformations in Europe--a population based study. Acta Obstet Gynecol Scand. 2001;80:224-8.

34822 Allan LD, Apfel HD, Printz BF. Outcome after prenatal diagnosis of the hypoplastic left

349 heart syndrome. Heart. 1998;79:371-3.

35023 Galindo A, Nieto O, Villagra S, et al. Hypoplastic left heart syndrome diagnosed in fetal life:

351 associated findings, pregnancy outcome and results of palliative surgery. Ultrasound Obstet 352 Gynecol. 2009;33:560-6.

35324 Khoshnood B, De Vigan C, Vodovar V, et al. Advances in medical technology and creation 354 of disparities: the case of Down syndrome. Am J Public Health. 2006;96:2139-44.

35525 Khoshnood B, Pryde P, Wall S, et al. Ethnic differences in the impact of advanced maternal 356 age on birth prevalence of Down syndrome. Am J Public Health. 2000;90:1778-81.

35726 Kuppermann M, Gates E, Washington AE. Racial-ethnic differences in prenatal diagnostic 358 test use and outcomes: preferences, socioeconomics, or patient knowledge? Obstet Gynecol. $359 \quad 1996 ; 87: 675-82$.

36027 Smith LK, Budd JL, Field DJ, Draper ES. Socioeconomic inequalities in outcome of 361 pregnancy and neonatal mortality associated with congenital anomalies: population based study. 362 Bmj.343:d4306.

36328 Dommergues M, Benachi A, Benifla JL, et al. The reasons for termination of pregnancy in 364 the third trimester. Br J Obstet Gynaecol. 1999;106:297-303.

36529 Marret H, Perrotin F, Descamps P, et al. [Medical abortion in the second and third trimester. 366 Report of 125 indications from 1992 to 1995]. J Gynecol Obstet Biol Reprod (Paris). 1999;28:24536752.

36830 Hyett J, Perdu M, Sharland G, et al. Using fetal nuchal translucency to screen for major 369 congenital cardiac defects at 10-14 weeks of gestation: population based cohort study. Bmj. 
$370 \quad 1999 ; 318: 81-5$.

37131 Weiner Z, Weizman B, Beloosesky R, et al. Fetal cardiac scanning performed immediately

372 following an abnormal nuchal translucency examination. Prenat Diagn. 2008;28:934-8.

$373 \quad 32$ Botto LD, Lin AE, Riehle-Colarusso T, et al. Seeking causes: Classifying and evaluating

374 congenital heart defects in etiologic studies. Birth Defects Res A Clin Mol Teratol. 2007;79:714-

37527.

37633 Houyel L, Khoshnood B, Anderson RH, et al. Population-based evaluation of a suggested

377 anatomic and clinical classification of congenital heart defects based on the International

378 Paediatric and Congenital Cardiac Code. Orphanet J Rare Dis. 2011;6:64. 
Table 1. Prenatal diagnosis and termination of pregnancy for fetal anomaly (TOPFA) for fetuses with congenital heart defects (CHD).

\begin{tabular}{|c|c|c|c|c|c|}
\hline & \multirow[t]{2}{*}{$\mathrm{n}$} & \multicolumn{2}{|c|}{ Prenatal diagnosis } & \multicolumn{2}{|c|}{$\begin{array}{c}\text { Proportion of TOPFA among cases } \\
\text { with a prenatal diagnosis }\end{array}$} \\
\hline & & $\%$ & $95 \% \mathrm{Cl}$ & $\%$ & $95 \% \mathrm{Cl}$ \\
\hline All CHD & 1465 & 48 & $46-51$ & 46 & $42-50$ \\
\hline All Isolated CHD & 968 & 35 & $32-38$ & 16 & $12-19$ \\
\hline Isolated CHD-VSD excluded & 473 & 58 & $54-63$ & 27 & $22-32$ \\
\hline functionally univentricular CHD & 68 & 93 & $86-99$ & 60 & $48-72$ \\
\hline conotruncal defect & 53 & 72 & $59-84$ & 21 & $8-34$ \\
\hline complex CHD & 48 & 85 & $75-95$ & 34 & $19-49$ \\
\hline other CHD & 304 & 44 & $38-50$ & 11 & $5-16$ \\
\hline CHD associated with chromosomal anomalies & 230 & 79 & $74-84$ & 82 & $77-88$ \\
\hline CHD associated with anomalies of other systems* & 267 & 73 & $67-78$ & 53 & $46-60$ \\
\hline
\end{tabular}

* including genetic syndromes

379 
Table 2. Gestational age at prenatal diagnosis and at termination of pregnancy in fetuses with congenital heart defects.

\begin{tabular}{|c|c|c|c|c|c|}
\hline & All CHD & $\begin{array}{l}\text { Isolated CHD - VSD } \\
\quad \text { excluded }\end{array}$ & $\begin{array}{l}\text { CHD associated with } \\
\text { chromosomal anomalies }\end{array}$ & $\begin{array}{l}\text { CHD associated with anomalies } \\
\text { of other systems }\end{array}$ & $\mathrm{p}$ \\
\hline \multicolumn{6}{|c|}{ Gestational age at prenatal diagnosis (weeks) } \\
\hline mean $\left(S^{*}\right)$ & $20.4(0.26)$ & $21.9(0.39)$ & $19.1(0.38)$ & $21(0.51)$ & $<0.001$ \\
\hline median $\left(\mathrm{IQR}^{\S}\right)$ & $21(17-23)$ & $22(21-23)$ & $18(16-22.5)$ & $22(18-23)$ & $<0.001$ \\
\hline \multicolumn{6}{|c|}{ Gestational age at termination of pregnancy (weeks) } \\
\hline mean (SD*) & $23.2(0.29)$ & $24.8(0.46)$ & $21.7(0.45)$ & $24.1(0.55)$ & $<0.001$ \\
\hline median $\left(\mathrm{IQR}^{\S}\right)$ & $23(19-26)$ & $25(23-26)$ & $21.5(18-25)$ & $24(20-28)$ & $<0.001$ \\
\hline$\leq 22$ & $40 \%$ & $17 \%$ & $57 \%$ & $34 \%$ & \\
\hline $23-25$ & $30 \%$ & $45 \%$ & $22 \%$ & $30 \%$ & $<0.001$ \\
\hline$\geq 26$ & $30 \%$ & $38 \%$ & $21 \%$ & $36 \%$ & \\
\hline \multicolumn{6}{|c|}{$\begin{array}{l}\text { Time interval between prenatal diagnosis and termination } \\
\text { of pregnancy (weeks) }\end{array}$} \\
\hline mean $\left(S D^{*}\right)$ & $2.8(0.14)$ & $2.8(0.26)$ & $2.6(0.21)$ & $3.1(0.3)$ & 0.4 \\
\hline median $\left(\mathrm{IQR}^{\S}\right)$ & $2(1-3)$ & $2(1-4)$ & $2(1-3)$ & $2(1-4)$ & 0.6 \\
\hline
\end{tabular}


381

Table 3. Association between the odds of TOPFA and maternal socioeconomic and clinical factors in fetuses with isolated CHD-VSD excluded.

\begin{tabular}{|c|c|c|c|c|}
\hline & $\mathrm{n}$ & $\%$ of TOPFA & $95 \% \mathrm{Cl}$ & $p$ \\
\hline \multicolumn{5}{|l|}{ Maternal age } \\
\hline$\leq 34$ & 184 & 24 & $18-31$ & \multirow{3}{*}{0.5} \\
\hline $35-37$ & 43 & 32 & $18-47$ & \\
\hline$\geq 38$ & 47 & 30 & $16-43$ & \\
\hline \multicolumn{5}{|l|}{ Gravidity } \\
\hline primigravida & 99 & 27 & $20-33$ & \multirow{2}{*}{0.8} \\
\hline multigravida & 175 & 26 & $18-36$ & \\
\hline \multicolumn{5}{|l|}{ Maternal geographic origin } \\
\hline France & 152 & 33 & $25-40$ & \multirow{3}{*}{0.003} \\
\hline Africa & 66 & 11 & $3-18$ & \\
\hline Other & 56 & 28 & $16-40$ & \\
\hline \multicolumn{5}{|l|}{ Maternal occupation } \\
\hline professional & 91 & 31 & $21-40$ & \multirow{4}{*}{0.12} \\
\hline intermediate & 36 & 25 & $11-39$ & \\
\hline administrative / public service & 51 & 25 & $13-38$ & \\
\hline none & 74 & 15 & $6-23$ & \\
\hline \multicolumn{5}{|l|}{ Intra-uterine growth retardation } \\
\hline no & 265 & 26 & $21-31$ & \multirow{2}{*}{0.09} \\
\hline yes & 10 & 50 & $17-82$ & \\
\hline \multicolumn{5}{|l|}{ Nuchal translucency measurement } \\
\hline normal & 206 & 28 & $22-34$ & \multirow{3}{*}{0.27} \\
\hline abnormal & 17 & 35 & $12-59$ & \\
\hline not measured & 31 & 16 & $3-29$ & \\
\hline \multicolumn{5}{|c|}{ Gestational age at prenatal diagnosis (weeks) } \\
\hline$>22$ & 167 & 17 & $11-23$ & \multirow{2}{*}{$<0.001$} \\
\hline$\leq 22$ & 108 & 42 & $32-51$ & \\
\hline \multicolumn{5}{|l|}{ Category of CHD } \\
\hline other & 133 & 11 & $5-16$ & \multirow{4}{*}{$<0.001$} \\
\hline functionally univentricular $\mathrm{CHD}$ & 63 & 60 & $48-72$ & \\
\hline conotruncal CHD & 38 & 21 & $8-34$ & \\
\hline complex CHD & 41 & 34 & $19-49$ & \\
\hline
\end{tabular}


Table 4. Logistic regression analyses of the association between the odds of TOPFA and maternal socioeconomic and clinical factors in fetuses with prenatally diagnosed isolated CHD-VSD excluded.

\begin{tabular}{|c|c|c|c|c|}
\hline & Unadjusted OR & $95 \% \mathrm{Cl}$ & Adjusted OR & $95 \% \mathrm{Cl}$ \\
\hline \multicolumn{5}{|l|}{ Maternal age } \\
\hline$\leq 34$ & 1.0 & ref. & 1.0 & ref. \\
\hline $35-37$ & 1.5 & $0.7-3.1$ & 1.0 & $0.3-3.2$ \\
\hline$\geq 38$ & 1.3 & $0.6-2.7$ & 1.5 & $0.5-4.0$ \\
\hline \multicolumn{5}{|l|}{ Maternal geographic origin } \\
\hline France & 1.0 & ref. & 1.0 & ref. \\
\hline Africa & 0.2 & $0.1-0.6$ & 0.1 & $0.02-0.4$ \\
\hline Other & 0.8 & $0.4-1.6$ & 0.8 & $0.3-2.3$ \\
\hline \multicolumn{5}{|l|}{ Maternal occupation } \\
\hline professional & 1.0 & ref. & 1.0 & ref. \\
\hline intermediate & 0.7 & $0.3-1.8$ & 0.7 & $0.2-2.2$ \\
\hline administrative / public service & 0.8 & $0.3-1.7$ & 1.2 & $0.4-3.6$ \\
\hline none & 0.4 & $0.2-0.8$ & 0.5 & $0.1-1.6$ \\
\hline \multicolumn{5}{|l|}{ Intra-uterine growth retardation } \\
\hline no & 1.0 & ref. & 1.0 & ref. \\
\hline yes & 2.8 & $0.8-10.1$ & 6.6 & $0.9-51.0$ \\
\hline \multicolumn{5}{|l|}{ Nuchal translucency measurement } \\
\hline normal & 1.0 & ref. & 1.0 & ref. \\
\hline abnormal & 1.3 & $0.5-3.9$ & 1.5 & $0.3-6.2$ \\
\hline not measured & 0.5 & $0.2-1.3$ & 1.2 & $0.2-5.0$ \\
\hline \multicolumn{5}{|l|}{ Gestational age at prenatal diagnosis } \\
\hline$>22$ & 1.0 & ref. & 1.0 & ref. \\
\hline$\leq 22$ & 3.4 & $1.9-5.9$ & 3.2 & $1.4-7.1$ \\
\hline \multicolumn{5}{|l|}{ Category of CHD } \\
\hline other & 1.0 & ref. & 1.0 & ref. \\
\hline functionally univentricular CHD & 12.9 & $6.1-27.3$ & 21.3 & $7.7-59.0$ \\
\hline conotruncal CHD & 2.3 & $0.9-5.9$ & 2.1 & $0.7-6.6$ \\
\hline complex CHD & 4.4 & $1.9-10.3$ & 5.7 & $1.8-17.4$ \\
\hline
\end{tabular}

382 
Table 5. Association between gestational age at TOPFA and maternal socioeconomic and clinical factors in fetuses with isolated CHD-VSD excluded.

\begin{tabular}{|c|c|c|c|c|}
\hline & $\mathrm{n}$ & $\begin{array}{l}\text { mean } \\
\text { gestational age }\end{array}$ & SD & $\mathrm{p}$ \\
\hline \multicolumn{5}{|l|}{ Maternal age } \\
\hline$\leq 34$ & 45 & 24.7 & 0.5 & \multirow{3}{*}{0.9} \\
\hline $35-37$ & 14 & 24.5 & 1.2 & \\
\hline$\geq 38$ & 14 & 25.6 & 1.3 & \\
\hline \multicolumn{5}{|l|}{ Gravidity } \\
\hline Primigravida & 27 & 24.0 & 0.5 & \multirow{2}{*}{0.2} \\
\hline Multigravida & 46 & 25.3 & 0.7 & \\
\hline \multicolumn{5}{|l|}{ Maternal geographic origin } \\
\hline France & 50 & 24.8 & 0.6 & \multirow{3}{*}{0.8} \\
\hline Africa & 7 & 24.0 & 1.7 & \\
\hline Other & 16 & 25.1 & 0.9 & \\
\hline \multicolumn{5}{|l|}{ Maternal occupation } \\
\hline professional & 28 & 24.3 & 0.8 & \multirow{4}{*}{0.4} \\
\hline intermediate & 9 & 27.1 & 1.6 & \\
\hline administrative / public service & 13 & 25.1 & 1.1 & \\
\hline none & 11 & 24.8 & 0.9 & \\
\hline \multicolumn{5}{|l|}{ Intra-uterine growth retardation } \\
\hline no & 69 & 24.8 & 0.5 & \multirow{2}{*}{0.7} \\
\hline yes & 5 & 24.2 & 1.6 & \\
\hline \multicolumn{5}{|l|}{ Nuchal translucency measurement } \\
\hline normal & 58 & 25.3 & 0.5 & \multirow{3}{*}{0.13} \\
\hline abnormal & 6 & 22.0 & 1.1 & \\
\hline not measured & 5 & 24.8 & 2.0 & \\
\hline \multicolumn{5}{|l|}{ Type of CHD } \\
\hline other & 14 & 24.2 & 1.3 & \multirow{4}{*}{0.13} \\
\hline functionally univentriclar CHD & 38 & 25.2 & 0.6 & \\
\hline conotruncal CHD & 8 & 26.9 & 1.3 & \\
\hline complex CHD & 14 & 23.1 & 1.1 & \\
\hline
\end{tabular}

383 